"Rivadeneira con Sociedad Legal Minera Milagro Uno de Matancilla"

Recurso de casación

MATERIA: El cambio de jurisprudencia en materia de competencia judicial para conocer de las acciones civiles por accidentes del trabajo.

Disposiciones APLiCABles: Artículos 69 Ley 16.744 y 420 letra f del Código del Trabajo.

Doctrina: Es competente el juez del trabajo o el juez civil con competencia en lo laboral para conocer de la acción de responsabilidad deducida por el trabajador en un accidente del trabajo. Si la acción es deducida por otras personas distintas del trabajador, como la cónyuge, los hijos, los padres, hermanos del trabajador fallecido o afectado por un accidente del trabajo es competente el juez civil.

\title{
COMENTARIO:
}

\section{LA COMPETENCIA DE LOS TRIBUNALES PARA CONOCER DE LAS ACCIONES CIVILES POR ACCIDENTES DEL TRABAJO}

\section{Alejandro Romero Seguel ${ }^{1}$}

\section{EL ORIGEN DEL PROBLEMA}

En la aplicación de la ley de accidentes del trabajo se ha suscitado una larga discusión acerca de la competencia judicial. El debate gira en torno a si es un tema de competencia laboral o de la judicatura civil ordinaria.

En el plano normativo la regulación de la competencia para este tema se contiene en dos normas: el art. 69 de la Ley 16.744 y el art. 420 letra f) del C. Trabajo. En relación a este último precepto, la Ley $\mathrm{N}^{\circ}$ 19.447 (publicada el 8 de febrero de 1996), realizó una modificación con el objeto de poner fin a una disputa jurisprudencial. Según el art. 420

Doctor en Derecho, Universidad de Navarra, Profesor de Derecho Procesal, Universidad de los Andes. 
letra f) del CT. son de competencia laboral: "los juicios en que se pretenda hacer efectiva la responsabilidad del empleador derivada de accidentes del trabajo o enfermedades profesionales, con excepción de la responsabilidad extracontractual, a la cual le será aplicable lo dispuesto en el artículo 69 de la Ley $N^{\circ} 16.744^{\prime \prime}$.

Hasta antes de promulgarse la Ley $\mathrm{N}^{\circ} 19.447$, se discutía si el juez laboral era competente para conocer de la mencionada responsabilidad extracontractual. La duda surgía a raíz de lo dispuesto en el artículo 69 de la Ley $\mathrm{N}^{\circ} 16.744$, que ordenaba que la determinación de la naturaleza y cuantía de los perjuicios, y el monto de las correspondientes indemnizaciones, se hiciera "con arreglo a las prescripciones del derecho común".

La referida modificación legal zanjó la discusión, al ampliar expresamente el conocimiento de los juzgados laborales a los juicios en que se pretenda hacer efectiva la responsabilidad contractual del empleador y excluyendo, expresamente también, los casos en que se reclame responsabilidad extracontractual, incluso respecto del propio empleador.

En consecuencia, actualmente para determinar la competencia en este tipo de juicios hay que distinguir:

\section{$1^{\circ}$ ) Si la acción de perjuicios es deducida por el trabajador}

Es competente el juez del trabajo o el juez civil con competencia en lo laboral, en ambos casos aplicando el procedimiento laboral. El fundamento de esta competencia proviene de la contractualización que se ha hecho del deber de seguridad, como parte integrante del contrato de trabajo que un empleador suscribe con el trabajador. El art. 184 del Código del Trabajo es la base legal para esta solución.

$2^{\circ}$ ) Si la acción es deducida por otras personas distintas del trabajador, como la cónyuge, los hijos, los padres, hermanos del trabajador fallecido o afectado por un accidente del trabajo

En estos casos se trata de terceros ajenos a la relación laboral, que tratan de obtener una condena de perjuicios, de conformidad al régimen especial de responsabilidad civil previsto en el art. 69 de la Ley $\mathrm{N}^{\circ}$ 16.744 .

La jurisprudencia había sido fluctuante en este tema, pero en el último tiempo se ha uniformado, en el sentido de declarar la incompetencia para el evento que deduzcan en sede laboral su pretensiones personas diversas del trabajador.

Antes del cambio jurisprudencial que motiva este comentario, para otorgarles competencia a los juzgados del trabajo se calificaba como 
"contractual" a las acciones deducidas por estos terceros. Una clara exposición de este criterio se contiene en la sentencia de la CS. de 11 de julio de $2000^{2}$ :

"Cuarto: Que, de este modo, el fundamento sobre el que se sostiene la sentencia impugnada, es erróneo, puesto que como se dejó establecido en el motivo anterior, el demandante acciona en virtud del deber de protección que consagra el artículo 184 del Código del Trabajo en favor de su hijo, en virtud del vínculo de subordinación y dependencia que unía a este con la demandada, razón por la cual es evidente que resulta competente para conocer de dicha acción un tribunal del trabajo, en conformidad a lo dispuesto en el artículo 420 f) del Código del ramo norma de carácter procesal, vigente a la época de la decisión.

Quinto: Que, además, cabe tener presente que, como este Tribunal lo ha decidido ya, ante el incumplimiento por parte del empleador de una de las obligaciones de la esencia de un contrato laboral, el legislador ha previsto el subsiguiente resarcimiento para el o los afectados, consagrando la acción pertinente en la Ley $\mathrm{N}^{\circ}$ 16.744, sobre Seguro Social contra Riesgos de Accidentes del Trabajo y Enfermedades Profesionales, artículo 69, que prescribe: "Cuando el accidente o enfermedad se deba a culpa o dolo de la entidad empleadora o de un tercero, sin perjuicio de las acciones criminales que procedan, deberán observarse las siguientes reglas:... b) la víctima y las demás personas a quienes el accidente o enfermedad cause daño podrán reclamar al empleador o terceros responsables del accidente, también las otras indemnizaciones a que tengan derecho, con arreglo a las prescripciones del derecho común, incluso el daño moral". Es decir, esta norma consagra la posibilidad de obtener indemnización de perjuicios, cuando ellos han sido causados por el incumplimiento del deber de protección a la vida y salud del trabajador, cometido por el empleador y concede tal acción no solo al propio afectado, sino a las demás personas a quienes el accidente cause daño.

Sexto: Que, en esta línea de deducciones, resulta evidente que el fallo impugnado ha vulnerado las disposiciones contenidas en los artículos 420 f) del Código del Trabajo y 69 de la Ley $\mathrm{N}^{\circ} 16.744$, desde que conforme a tales normas, son los juzgados del trabajo los llamados a conocer y fallar las causas en que se deduce una acción que tiene por fundamento el deber de protección y seguridad, im-

RDJ, t. XCVII, sec. $3^{2}$, pp. 119-120. 
puesto por el legislador al empleador, deber que se encuentra consagrado en el artículo 184 del Código del ramo, norma que, si bien no se menciona en el recurso en análisis, ha sido, evidentemente, quebrantada también.

\section{EL CAMBIO EN LA JURISPRUDENCIA}

La tesis anterior ha sido cambiada radicalmente por la reciente jurisprudencia de la E. Corte Suprema, criterio que a la fecha de este comentario se había plasmado en sucesivas sentencias.

\section{a) Sentencia del 19 de agosto de 2003}

En este caso, ante el Juzgado de Letras de Illapel, en autos rol $\mathrm{N}^{\circ}$ 9.736-01, doña Erika del Carmen Rivadeneira Carvajal dedujo demanda en contra de la Sociedad Legal Minera Milagro Uno de Matancilla y en contra de una persona natural, como responsable subsidiario. Su demanda buscaba se condenara a los demandados a pagarle por concepto de indemnización de perjuicios causados con motivo del accidente de trabajo que sufrió su cónyuge y a consecuencia del cual este falleció. Los demandados, contestando la demanda, opusieron las excepciones de incompetencia del tribunal, ineptitud del libelo, beneficio de excusión y la ausencia de la calidad de dueño de la obra o faena en el caso del demandado subsidiario, falta de legitimación activa de la demandante, inexistencia del presupuesto de hecho que legitima la demanda. En subsidio la rebaja de montos por exposición imprudente al daño.

El Tribunal de primera instancia, en sentencia de 19 de julio de 2002, acogió la excepción de incompetencia alegada por los demandados, rechazando, en consecuencia, la demanda.

Se alzaron ambas partes y la Corte de Apelaciones de La Serena, en fallo de 16 de octubre del 2002, confirmó la de primer grado. La demandante dedujo recurso de casación en el fondo en contra de la sentencia de segunda instancia, pidiendo que se la invalide y se dicte la de reemplazo que rechace la excepción de incompetencia y se pronuncie sobre el fondo del asunto acogiendo la demanda.

Admitido a tramitación el recurso, sobre el tema que nos interesa la Corte Suprema resolvió:

"Primero: Que el demandante apoya el recurso de casación en el fondo que deduce, en el quebrantamiento de los artículos 184, 420 a) y f) del Código del Trabajo y artículo 69 de la Ley $\mathrm{N}^{\circ} 16.744$. Argumenta que el artículo 420 a) contiene la norma general de competencia, disponiendo que son de atribución de los juzgados 
laborales, el conocimiento de las cuestiones suscitadas entre empleadores y trabajadores por aplicación de las normas laborales, circunstancia aplicable al caso, ya que se acreditó que el trabajador fallecido laboró para la demandada principal y que la indemnización de perjuicios reclamada tiene por objeto resarcir a su cónyuge sobreviviente de los daños materiales y morales sufridos y que le asisten, por cuanto el trabajador, cumpliendo una orden de su empleador, sufrió un accidente del trabajo que le causó la muerte. Alega que fluye que la demandante, en su calidad de sucesora y continuadora del trabajador, persigue el pago de una indemnización que tiene como fuente la relación laboral que ligó al trabajador con la sociedad legal minera demandada, por lo tanto, se encuadra dentro de la responsabilidad contractual, responsabilidad de conocimiento de los juzgados laborales, de acuerdo al artículo 420 f) del Código del ramo. Añade que la responsabilidad perseguida también tiene su origen en el artículo 184 del Código citado y que no es óbice a ello la disposición contenida en el artículo 69 de la Ley $\mathrm{N}^{\circ} 16.744$, pues ella no establece una regla de competencia, sino que se refiere al derecho común entendido en lo sustantivo. Por último, indica que son los hechos los que determinan la competencia. Finaliza señalando que los errores denunciados han influido sustancialmente en lo dispositivo del fallo, puesto que de no haberse incurrido en ellos se habría revocado la sentencia de primera instancia, rechazando la excepción de incompetencia opuesta por los demandados y, por consiguiente, se hubiera entrado a conocer del fondo del asunto acogiendo la demanda.

Segundo: Que, en la sentencia impugnada, se estableció como hecho que la demandante de autos es la cónyuge sobreviviente de Rubén Ignacio Rozas Godoy, fallecido en el interior de la pertenencia minera Naty, a consecuencia de los trabajos con explosivos que realizaba en sus funciones de perforo y que era trabajador dependiente de la Sociedad Legal Minera Milagro Uno de Matancilla.

Tercero: Que sobre la base de los hechos descritos precedentemente, los jueces del fondo, considerando que la actora es un tercero que no tiene ni ha acreditado relación laboral alguna con el demandado y que ejerce su acción en calidad de cónyuge sobreviviente de un trabajador fallecido, por el daño moral que arguye como basamento de su acción, estimaron que ella es de las señaladas como excepción en el artículo 420 f) del Código del Trabajo, a las cuales se les aplica el artículo 69 de la Ley $\mathrm{N}^{\circ} 16.744$, por cuanto se trata de hacer efectiva una responsabilidad de naturaleza extracontractual. Por tales motivos acogieron la excepción de incompetencia opuesta por los demandados y, en consecuencia, rechazaron la demanda deducida en estos autos. 
Cuarto: Que, conforme a lo anotado, la controversia de derecho se circunscribe a determinar la naturaleza de la responsabilidad que se pretende hacer efectiva en estos autos. Realizada esa precisión deberá establecerse si los juzgados laborales son competentes o no para conocer de este litigio.

Quinto: Que la responsabilidad contractual es la que emana de la existencia de un vínculo previo entre la parte que reclama la indemnización y aquella a la cual se la demanda, y la responsabilidad extracontractual es aquella que deriva de un hecho ilícito que ha inferido injuria o daño en la persona o propiedad de otro. En ambos casos, establecidos sus requisitos de procedencia, conducen al resarcimiento respectivo, pero, en la primera de ellas, necesariamente debe existir una vinculación entre las partes y, en la segunda, tal nexo no se presenta. Cabe destacar, además, que en la especie, si bien las partes se ligan por un contrato de trabajo, esto es, por una convención por la cual el empleador y el trabajador se obligan recíprocamente, este a prestar servicios personales bajo dependencia y subordinación del primero, y aquel a pagar por estos servicios una remuneración determinada, no puede estimarse que la responsabilidad del empleador derive, propiamente, de esa convención, sino que al suscribirse un contrato de naturaleza laboral, los contratantes quedan obligados por todas las leyes que rigen la materia y es esta legislación laboral la que establece el deber u obligación de seguridad para el empleador.

Sexto: Que, según se estableció como hecho, la demandante es un tercero que no tiene ni ha acreditado relación laboral alguna con el demandado. No se trata de una cuestión entre trabajador y empleador, ni tampoco se ha ejercido acción en calidad de sucesora del dependiente afectado. Es decir, ciertamente entonces, la cónyuge sobreviviente del trabajador fallecido pretende hacer efectiva una responsabilidad de naturaleza extracontractual, ya que ninguna vinculación la ha unido al demandado principal, por ende, no puede considerarse, en este caso, que la proteja la obligación que recae sobre el empleador de adoptar todas las medidas de seguridad pertinentes.

Séptimo: Que, establecida la naturaleza de la responsabilidad de que se trata, corresponde determinar la competencia de los juzgados laborales para conocer de este pleito. Al respecto, cabe traer a colación la norma contenida en el artículo 420 f) del Código del Trabajo, que establece: Serán de competencia de los Juzgados de Letras del Trabajo: $f$ ) los juicios en que se pretenda hacer efectiva la responsabi- 
lidad del empleador derivada de accidentes del trabajo o enfermedades profesionales, con excepción de la responsabilidad extracontractual a la cual le será aplicable lo dispuesto en el artículo 69 de la Ley $\mathrm{N}^{\circ} 16.744$.

Octavo: Que dicha norma fue agregada al artículo 420 del Código del ramo, en virtud de la modificación introducida por el artículo 1 $\mathrm{N}^{\circ} 3$ de la Ley $\mathrm{N}^{\circ} 19.447$, de 8 de febrero de 1996. El Mensaje de S.E., el Presidente de la República, con el cual esta ley fue enviada al Congreso Nacional, decía en lo pertinente: Se aclara expresamente la competencia que los juzgados laborales tienen para conocer de aquellas causas en que se persigue la responsabilidad contractual derivada de accidentes del trabajo o enfermedades profesionales. Al hacerlo así, se está reconociendo lo que parte importante de la jurisprudencia de nuestros tribunales ha sostenido al resolver las causas que en esta materia se han sometido a su conocimiento. Esta precisión tiende a dar mayor certeza a las partes de la relación laboral acerca del ámbito de competencia de esta judicatura, garantizando así el más pleno ejercicio de los derechos que la ley consagra.

Noveno: Que siguiendo con el análisis de la historia fidedigna del establecimiento de esta ley, es dable consignar que, en la discusión general, el Subdirector del Trabajo expresó que el proyecto resuelve una cuestión de competencia y dispone que la responsabilidad contractual del empleador, esto es, la que se deriva del contrato de trabajo, es de competencia de los Juzgados del Trabajo, en tanto que la responsabilidad extracontractual corresponde a un juicio de lato conocimiento que es de competencia de los Juzgados Civiles. Además, en las actas respectivas se deja constancia que preocupó a la Comisión que la disposición propuesta usara la expresión responsabilidad contractual del empleador. El señor Subdirector del Trabajo señaló que esta norma tiene por objeto dilucidar una controversia que se ha suscitado con frecuencia entre los Juzgados del Trabajo y los Juzgados Civiles respecto a cuáles son los tribunales competentes para conocer de los accidentes del trabajo. La jurisprudencia no ha sido uniforme. Por ello la norma propone separar la responsabilidad contractual de lo que es la responsabilidad extracontractual. En primer lugar, porque en ambas la calificación del dolo y la culpa es distinta $y$, en segundo término, porque en una o en otra la posibilidad del daño moral es diferente. En consecuencia, hay una separación que es fundamental efectuar. La responsabilidad extracontractual debe ser de competencia de los Tribunales Civiles en un juicio de lato conocimiento. Por el contrario, la responsabilidad que deriva del contrato de trabajo, específicamente de lo dispuesto en el 
artículo 184 del Código del Trabajo, en cuanto a que el empleador está obligado a tomar todas las medidas necesarias para proteger eficazmente la vida y salud de los trabajadores, manteniendo las condiciones adecuadas de higiene y seguridad en las faenas, debe ser de competencia de los Juzgados del Trabajo.

Décimo: Que el Honorable Senador, señor Thayer, estimó que no sería conveniente hacer una referencia expresa a la responsabilidad contractual, porque el solo hecho de que se celebre un contrato de trabajo, liga al trabajador y al empleador a toda la normativa legal que ampara la seguridad en el trabajo. No son responsabilidades que emanan de lo que han contratado las partes, sino que de lo dispuesto en la ley como consecuencia de existir un contrato de trabajo. En cuanto a la responsabilidad extracontractual es evidente que tiene que estar excluida de la competencia de los tribunales del trabajo, por cuanto su determinación requiere un juicio de lato conocimiento y debe por su naturaleza estar entregada a las prescripciones del derecho común, puesto que en ella puede haber terceros involucrados como responsables del accidente, dando lugar a otras indemnizaciones.

Undécimo: Que, en fin, se estimó conveniente contemplar la norma propuesta suprimiendo la mención al carácter contractual de la responsabilidad del empleador y agregar que esta competencia será con exclusión de la responsabilidad extracontractual, a la cual le será aplicable lo dispuesto en el artículo 69 de la Ley $\mathrm{N}^{\circ} 16.744$, quedando, el artículo como ya se transcribió.

Duodécimo: Que, en consecuencia, ha de estimarse que la acción deducida en estos autos tendiente a hacer efectiva la responsabilidad extracontractual a título personal, por la cónyuge sobreviviente de un trabajador fallecido, no es de la competencia de los juzgados laborales, de manera que, al así decidirlo, la sentencia recurrida no ha cometido error de derecho alguno, por lo tanto, deberá desestimarse la nulidad de fondo intentada por la demandante.

Decimotercero: Que, a mayor abundamiento, cabe indicar que, si bien la actora argumenta en su libelo que la responsabilidad que persigue deriva del incumplimiento por parte del empleador respecto de su cónyuge fallecido del deber de seguridad establecido en el artículo 184 del Código del Trabajo, tal mención resulta insuficiente para hacer competente al Juzgado del Trabajo, ya que, como se dijo, ningún nexo de naturaleza laboral la unió al demandado y no actúa como sucesora del afectado. Por estas consideraciones y lo dispuesto, además, en los artículos 463 del Código del Trabajo y 764, 765, 767, 772 y 783 del Código de Procedimiento Civil, se rechaza, sin 
costas, el recurso de casación en el fondo deducido por la demandante a fojas 163 , contra la sentencia de dieciséis de octubre de dos mil dos, que se lee a fojas 159. Regístrese y devuélvase. N 4.859-02. Pronunciada por la Cuarta Sala de la Corte Suprema integrada por los Ministros señores Marcos Libedinsky T., José Benquis C., Orlando Alvarez H., Urbano Marín V. y Jorge Medina C. Santiago, 19 de agosto de 2003.

\section{b) Sentencia del 26 de agosto de 2003}

El 26 de agosto de 2003 la Corte Suprema pronunció otra sentencia de similar orientación. En este caso el demandante accionaba en su calidad de padre de un trabajador fallecido, a objeto que las demandadas sean condenadas solidariamente, o en subsidio, de acuerdo a la norma del artículo 64 del Código del Trabajo, a indemnizarle los perjuicios por daño emergente, por lucro cesante y por daño moral. En su demanda explica que su hijo sufrió un accidente, mientras desempeñaba labores de mantenimiento del suministro eléctrico, lo que le ocasionó la muerte debido a asfixia por electrocución. La acción, desde el punto de vista legal se fundamenta en las normas que menciona de la Ley $\mathrm{N}^{\circ} 16.744$ y del Código del Trabajo, de este último, entre otras, artículo 184 y siguientes.

Tanto la demandada principal como la subsidiaria opusieron la excepción de incompetencia absoluta del tribunal en razón de la materia, fundándose en el artículo 420 f) del Código del Trabajo, aduciendo que se perseguía hacer efectiva una responsabilidad extracontractual.

La Corte Suprema admitió la alegación de incompetencia, señalando las mismas razones del fallo de 19 de agosto de 2003, esto es, "que la responsabilidad contractual es la que emana de la existencia de un vínculo previo entre la parte que reclama la indemnización y aquella a la cual se la demanda y la responsabilidad extracontractual es aquella que deriva de un hecho ilícito que ha inferido injuria o daño en la persona o propiedad de otro. En ambos casos, establecidos sus requisitos de procedencia, conducen al resarcimiento respectivo, pero, en la primera de ellas, necesariamente debe existir una vinculación entre las partes y, en la segunda, tal nexo no se presenta. Cabe destacar, además, que tratándose de materia laboral, si bien las partes se ligan por un contrato de trabajo, esto es, por una convención por la cual el empleador y el trabajador se obligan recíprocamente, este a prestar servicios personales bajo dependencia y subordinación del primero, y aquel a pagar por estos servicios una remuneración determinada, no puede estimarse que la responsabilidad del empleador derive, propiamente, de esa convención, sino que al suscribirse un contrato de naturaleza laboral, los contratantes quedan obligados por todas las leyes que rigen la materia y es esta legislación laboral la que impone el deber u obligación de seguridad al empleador". 
En este caso, el demandante era un tercero que no acreditó relación Iaboral alguna con el demandado. Tampoco, según el fallo ejerció su acción en calidad de sucesor del dependiente afectado.

Los considerandos $5^{\circ}, 6^{\circ}, 7^{\circ}, 8^{\circ}, 9^{\circ}, 10^{\circ}$ de este fallo son idénticos a los de la sentencia del 19 de agosto. La sentencia fue pronunciada por la Cuarta Sala de la Corte Suprema integrada por los Ministros señores Marcos Libedinsky T., José Benquis C., Orlando Alvarez H., Urbano Marín V. y Jorge Medina C.

\section{c) Sentencia de 11 de mayo de 2004}

En los autos caratulados "Poblete Bahamóndez Angie", conociendo la Corte Suprema de una casación laboral (Rol 2.610-03), procedió a anular de oficio todo lo obrado en un juicio laboral. Dichos autos habían sido iniciados por una hija, reclamando una indemnización en contra del empleador, a consecuencia del homicidio de su madre en un asalto ocurrido en su lugar de trabajo ${ }^{3}$.

\section{ALGUNAS CONSECUENCIAS PRÁCTICAS DE ESTA DOCTRINA JURISPRU- DENCIAL}

Alguna de las consecuencias de este cambio de interpretación en la normativa procesal más importantes son:

$1^{\circ}$ ) Aparece una causal objetiva para desestimar en el estudio de admisibilidad el recurso de casación en el fondo

Como se sabe, conforme a la facultad del artículo 782 del CPC, es competencia de cada una de las salas de la Corte Suprema, en el segundo estudio de admisibilidad del recurso de casación en el fondo, poder rechazarlo de inmediato, si en opinión unánime de sus integrantes, adolece de una manifiesta falta de fundamentos.

Lo que en principio aparece como una facultad con un amplio margen de discrecionalidad, ha podido ser utilizada para fortalecer el rol de la jurisprudencia, como ocurre en este caso.

Si algún litigante quisiera cuestionar, por la vía de casación, una decisión de los jueces del fondo que aplicaran el criterio plasmado a partir del fallo de 19 agosto de 2003, el recurso podría ser declarado inadmisible preliminarmente.

CS. 11 de mayo de 2004 , GJ, 287, p. 259. 
Esta consecuencia que se propone cuenta con algunos ejemplos prácticos, que se han dado en otras materias. Un ejemplo consta en la resolución de la Cuarta Sala, de 16 de julio de 1998 (Rol N².080/98). Allí se declaró inadmisible un recurso de casación en el fondo interpuesto en un proceso laboral, que denunciaba como infracción de ley una materia sobre la cual la sala ya tenía opinión formada (relativa a si las metas impuestas contractualmente por la empresa pueden configurar un incumplimiento grave de las obligaciones del trabajador). Para lo que interesa se resolvió: "(...) el despido del que ha sido objeto la actora es injustificado acorde, además con la jurisprudencia reiterada de esta Sala en relación con este aspecto de derecho impugnado en el recurso, por lo que, de conformidad con lo prevenido en el inc. $2^{\circ}$ del artículo 782 del Código de Enjuiciamiento Civil deberá rechazarse el expresado recurso por adolecer de manifiesta falta de fundamento".

En otra oportunidad, con fecha 26 de agosto de 1998, la misma Sala desestimó -por manifiesta falta de fundamentos- un recurso de casación en el fondo, argumentando que la decisión de los jueces del fondo estaba acorde "con la reiterada jurisprudencia establecida sobre esta materia" (Rol $\mathrm{N}^{\circ}$ 2.763-98).

Este fallo es interesante por dos motivos. Uno. Porque la sentencia de la Corte de Apelaciones de Santiago había confirmado la de primer grado utilizando como argumento un precedente, al sostener que " $1{ }^{\circ}$ Que la jurisprudencia corrobora las conclusiones del fallo, como por ejemplo la sentencia de la Corte Suprema recaída en el Recurso de Casación en el Fondo (...) que manifiesta que el incremento de carácter remuneracional establecido en el art. 2 del Decreto Ley 3501, solo tuvo por finalidad mantener el monto líquido de la remuneración de los trabajadores, a raíz del traspaso a estos de la carga impositiva...". En segundo lugar, porque los justiciables a quienes se les aplicó el valor del precedente era un grupo de funcionarios judiciales, incluidos Ministros de la Corte Suprema y Ministros de Cortes de Apelaciones, que habían demandado al Fisco de Chile para obtener la reliquidación de un desahucio anticipado pagado a cada uno de los actores en virtud de la Ley $\mathrm{N}^{\circ}$ 18.681. (Autos caratulados "Díaz Osvaldo y otros con Fisco", Rol $\mathrm{N}^{\circ}$ 2555-92 del $28^{\circ}$ Juzgado Civil de Santiago").

En consecuencia, la doctrina que se ha fijado sobre la competencia judicial debe ser mirado como un criterio objetivo acerca de lo que debe entenderse por manifiesta falta de fundamento -ir contra jurisprudencia de la sala-, y justifica la declaración preliminar de un recurso de casación en el fondo que quiera contrariar tal criterio.

\section{$2^{\circ}$ ) La declaración de oficio de la falta de competencia}

No se debe olvidar que las normas legales que regulan la competencia hacen efectiva la garantía constitucional de no ser juzgado por comi- 
siones especiales (art. $19 \mathrm{~N}^{\circ} 4$ inc. $\left.4^{\circ} \mathrm{CPE}^{\circ}\right)^{4}$. La garantía de un juez predeterminado por la ley es una herencia de la Revolución Francesa, que se materializa en una estricta reserva de ley para determinar el juez que debe resolver un determinado conflicto. Se infringiría gravemente este derecho fundamental si se intentara desconocer, a través de una interpretación judicial, una norma de competencia que cuenta con una línea jurisprudencial que ha fijado su genuino sentido y alcance (arts. $7^{\circ}$ y 73 CPE).

Al tratarse de una interpretación que incide en uno de los factores que regulan la competencia absoluta, el tribunal debe declarar de oficio tal incompetencias.

Cfr. Corte de Ap, de Valparaíso, 21 de junio de 1988, RDJ, 1988, sec. 5ª p. 276.

Sobre el tema, Colombo CAmpbell, Juan, La competencia, $2^{\text {z }}$ ed. A. y a., Santiago, Editorial Jurídica de Chile, 2004, pp, 171-179. 